\title{
A REGULAÇÃO ECONÔMICA DA MÍDIA: PARLAMENTARES PROPRIETÁRIOS DE EMISSORAS DE RÁDIO E TELEVISÃO, E O ARRENDAMENTO DA GRADE DE PROGRAMAÇÃO ÀS IGREJAS ${ }^{1}$
}

THE ECONOMIC REGULATION OF THE MEDIA: PARLIAMENTARY OWNERS OF RADIO AND TELEVISION BROADCASTORS, AND THE LEASE OF THE PROGRAMMING GRID TO

CHURCHES

Maria Laura Felicio de ALMEIDA ${ }^{2}$

Fábio Cantizani GOMES ${ }^{3}$

ISSUE DOI: $10.21207 / 2675-0104.2018 .789$

\begin{abstract}
RESUMO
O principal objetivo desta pesquisa de iniciação científica é elucidar questões controvertidas em torno da regulação da mídia no Brasil. Ademais, o trabalho analisa os diversos problemas no setor da comunicação, com ênfase na prática ilegal de aluguel da grade de programação das emissoras de rádio e televisão às igrejas, para a veiculação de conteúdos religiosos/proselitistas, e na presença de parlamentares detentores de mandato eletivo donos ou sócios de emissoras concessionárias do serviço

\footnotetext{
${ }^{1} \mathrm{O}$ presente artigo sintetiza a monografia de conclusão da pesquisa, realizada para o Programa Interno de Bolsas de Iniciação Científica (PIBIC 2017-2018) da Faculdade de Direito de Franca (FDF), Franca/SP.

${ }^{2}$ Discente da Faculdade de Direito de Franca (FDF), Franca/SP. Bolsista do Programa Interno de Bolsas de Iniciação Científica (PIBIC 2017-2018).

${ }^{3}$ Possui graduação em Direito pela Universidade Estadual Paulista Júlio de Mesquita Filho (1994) e mestrado em Direito pela Universidade Estadual Paulista Júlio de Mesquita Filho (2004). Doutorando pelo Centro Universitário de Bauru da Instituição Toledo de Ensino (2018). Atualmente é professor titular de Direito Constitucional da Faculdade de Direito de Franca e da Universidade de Franca. Tem experiência na área de Direito, com ênfase em Direito Constitucional.
} 
de radiodifusão. Através da pesquisa bibliográfica e, subsidiariamente, do levantamento de dados, percebeu-se que as leis responsáveis por disciplinar a comunicação social não impedem a formação de oligopólios e propriedade cruzada nem reduzem a influência de grupos políticos e religiosos dentro da mídia.

Palavras-chave: Comunicação Social; Regulação da Mídia; Regime Democrático.

\section{ABSTRACT}

The main purpose of this undergraduate research is to elucidate controversial issues surrounding media regulation in Brazil. Furthermore, the paper analyzes the various problems in the communication sector, with an emphasis on the illegal practice of renting the broadcasting program to churches, in order to spread religious, proselytizing contents, and on the presence of elected representatives as owners or members of broadcasting service. Through bibliographic research and data collection, it has been noticed that the laws responsible for disciplining the media do not prevent the formation of oligopolies and cross-ownership, nor do they reduce the influence of political and religious groups within the media.

Keywords: Social Communication; Media Regulation; Democratic System.

\section{INTRODUÇÃO}

Nos países de tradição democrática, as notícias e informações circulam livremente pelos meios, juntamente com a divulgação de ideias e opiniões plurais. É inquestionável, portanto, a significativa função social dos meios de comunicação nos dias de hoje. No entanto, para que a mídia possa cumprir sua função dentro da sociedade, o setor da comunicação social deve observar regras dispostas em leis. A Constituição Federal de 1988 destinou aos meios de comunicação de massa um capítulo exclusivo para versar sobre a matéria.

Atualmente, os meios de comunicação evidenciam um cenário alarmante por causa da concentração de grupos hegemônicos na mídia. Os diversos problemas no setor da comunicação são conhecidos. Entretanto a pesquisa procurou explorar significativamente dois assuntos: a prática ilegal de arrendamento da grade diária da programação às Igrejas e a presença de parlamentares como proprietários de emissoras de rádio e televisão.

2 DIREITOS E LIBERDADES FUNDAMENTAIS

2.1 O ESTADO DEMOCRÁTICO DE DIREITO 
As revoluções dos séculos XVIII e XIX transformaram profundamente o cenário econômico, político e social da Europa. Os revolucionários derrubaram a monarquia absolutista e combateram privilégios concedidos a uma restrita classe de pessoas. Em contraposição ao modelo absolutista, o modelo liberal emergiu com a conquista de direitos pelos homens livres. Para Norberto Bobbio, os direitos dos homens "nascem no início da era moderna, juntamente com a concepção individualista da sociedade" 4 .

$\mathrm{Na}$ conjuntura do Estado Moderno, o modelo liberal é representado pelo Estado de Direito. O Estado Liberal de Direito é marcado pela sujeição do Estado à lei, que pauta a atuação estatal conforme as convicções do liberalismo. Em conformidade com Lenio Luiz Streck e José Luiz Bolzan de Morais, o "Estado de Direito sustenta juridicamente o conteúdo próprio do liberalismo, referendando a limitação da ação estatal e tendo a lei como ordem geral e abstrata" 5 .

Apesar de representar um notável progresso à civilização, o Estado de Direito, no decorrer dos anos, elevou o individualismo e aprofundou a desigualdade social. Como consequência, imensas mazelas sociais foram deixadas. Por fim, o Estado liberal se tornou insuficiente.

Nesse contexto, o Estado Social de Direito manifestou-se no começo do século XX, em contraposição ao Estado Liberal de Direito, para contestar o individualismo liberal, inaugurando a geração dos direitos sociais. Por meio do cumprimento de prestações, o Estado deveria garantir o bem social, e não mais se abster. Nada obstante, o Estado Social consegue comportar diferentes regimes políticos, incluindo os de natureza totalitária, por causa das diversas interpretações de seu conceito.

Posteriormente, surge o Estado Democrático de Direito. O conceito de Estado Democrático de Direito é formado a partir da reunião de elementos do Estado Liberal de Direito, e do Estado Social de Direito. Porém, o Estado Democrático os ultrapassa ao criar condições para transformar o quadro da sociedade. O Estado Democrático de Direito não somente reconhece direitos individuais, políticos e sociais, como também os concretiza ao criar condições para o seu exercício pleno.

A relevância dos direitos e fundamentais previstos na Constituição Federal de 1988 é notável. A eles foi reservado um capítulo próprio (além de outros artigos esparsos pelo texto constitucional), e o

\footnotetext{
${ }^{4}$ BOBBIO, Norberto. A Era dos Direitos. Tradução de Carlos Nelson Coutinho. Rio de Janeiro: Elsever, 2004. p 22.

${ }^{5}$ STRECK, Lenio Luiz; MORAIS, José Luis Bolzan de. Ciência Política e Teoria Geral do Estado. 2. ed. Porto Alegre: Livraria do Advogado, 2001. p. 94
} 
Estado se certifica em protegê-los e garanti-los a todos os cidadãos, e o consegue fazer por ocasião da consolidação do Estado Democrático de Direito.

A previsão de liberdades fundamentais dentro do texto constitucional e a disposição do Estado no sentido de garantir o exercício destas liberdades constituem um dos elementos capitais para a realização da dignidade da pessoa humana, um dos fundamentos do Estado Democrático de Direito, declarado no primeiro artigo da Constituição Federal. Esse modelo de Estado possibilita, também, a presença dos cidadãos nas decisões e no cotidiano político. Em virtude de os direitos e liberdades garantidos, a população aproxima-se das questões pertinentes ao Estado e ao interesse público.

\subsection{A LIBERDADE DE INFORMAÇÃO EM GERAL E A LIBERDADE DE INFORMAÇÃO JORNALÍSTICA}

A liberdade de informação em geral, base para o desenvolvimento do Estado Democrático de Direito, está prevista no rol dos direitos e garantias fundamentais da Constituição Federal de 1988, bem como em tratados e convenções internacionais dos quais o Brasil é país signatário. Por conseguinte, esta liberdade é compreendida de duas maneiras: a liberdade que cada cidadão tem de procurar informações, conhecimentos e esclarecimentos, e a liberdade que cada um tem de emitir opiniões e ideias, em qualquer tipo de meio de expressão, independentemente de qualquer tipo de censura. Corroborando com a tese, José Afonso da Silva afirma que,

a liberdade de informação compreende a procura, o acesso, o recebimento e a difusão de informações ou idéias, por qualquer meio, e sem dependência de censura, respondendo cada qual pelos abusos que cometer. $\mathrm{O}$ acesso à todos informação é direito individual consignado na Constituição Federal $[\ldots]^{6}$.

Na conjuntura atual, grande parte da comunicação humana se dá nos meios de comunicação de massa, lugar em que o debate da vida política efetivamente ocorre. A liberdade de informação, enquanto direito individual, concretiza-se nos diversos tipos de mídia existentes. Por causa

${ }^{6}$ SILVA, José Afonso. Curso de Direito Constitucional Positivo. $37^{\mathrm{a}}$ edição. São Paulo: Malheiros, 2014. p 236. 
disso, a mídia assume uma posição de prestígio dentro da sociedade, sobretudo em um regime democrático, pois é uma instituição capaz de veicular a agenda pública dos governos, de expor e fiscalizar os atos dos representantes eleitos pelo povo e, principalmente, a mídia possui o condão de formar a opinião pública.

No presente estágio do capitalismo, por ocasião do desenvolvimento de tecnologias capazes de facilitar e ampliar o relacionamento social, a informação transformou-se em mercadoria. $\mathrm{Na}$ sociedade da informação, os grupos econômicos são os verdadeiros responsáveis pelo fornecimento de direitos fundamentais. Deste modo, o Estado tem o dever de intervir e equilibrar o conflito entre a apropriação da informação por empresa e os direitos fundamentais, por isso a comunicação social possui um capítulo próprio na Constituição Federal $^{7}$.

Durante o processo de redemocratização do país, uma das principais pautas dos movimentos populares que lutavam pelo fim do regime ditatorial militar foi pela proibição de qualquer tipo de censura à liberdade de expressão. A mobilização social, no dizer de Vogel, foi bastante significativa na "construção de uma agenda política que teve forte repercussão durante os trabalhos da ANC" ${ }^{8}$. Deste modo, o caput do artigo 220 se encarrega de vedar qualquer tipo de restrição às liberdades individuais exercidas em qualquer meio de comunicação. Adiante, o $\S 1^{\circ}$ proíbe expressamente a censura prévia sobre qualquer veículo de informação jornalística e o $\S 2^{\circ}$ veda "toda e qualquer censura de natureza política, ideológica e artística".

Em seguida, o artigo 221 estabelece os princípios básicos a serem observados pelas emissoras de rádio e televisão. A grade de programação das emissoras deverá primar por conteúdos relacionados à educação, arte, cultura e informação, prezando pelo fomento da cultura nacional e regional, e pelo incentivo à produção de conteúdos independentes, prezando-se pela valorização da identidade cultural do povo brasileiro.

Conforme dados da PBM (Pesquisa Brasileira de Mídia), divulgados pela Secretaria de Comunicação Social em 2016, 63\% da população se informa através da televisão, sendo este o meio de comunicação favorito entre os brasileiros. A internet está em segundo

\footnotetext{
${ }^{7}$ NAPOLITANO, Carlo José. A regulação constitucional da comunicação social e a efetivação de suas normas. ALCEU: Revista de Comunicação, cultura e política, Rio de Janeiro, v. 12, n. 24, p.204215, jan./jun. 2012.

${ }^{8}$ VOGEL, Luiz Henrique. A comunicação social na constituição de 1988 e a concentração de mídia no Brasil (Consultoria Legislativa). Brasília: Câmara dos Deputados, 2013.
} 
lugar (26\%), logo após está o rádio $(7 \%)$ e os jornais $(3 \%)^{9}$. Estes dados não só demonstram a extrema relevância dos meios de comunicação de massa para o exercício de direitos fundamentais, como também evidenciam o papel central que a mídia ocupa na sociedade, como já havia dito Rui Barbosa há quase um século. Nada obstante, o progresso democrático e o exercício de direitos fundamentais estão em risco em razão do cenário grave e preocupante da mídia no Brasil.

O Coletivo Intervozes, em parceria com o MOM (Mídia Ownership Monitor), divulgou, no ano de 2017, uma pesquisa encarregada de monitorar o quadro de 50 redes de comunicação (redes de televisão, rádio, imprensa e internet). Os resultados demostram que cinco grupos empresariais detêm 26 dos 50 veículos de comunicação analisados. O grupo Globo possui 9, seguido do grupo Bandeirantes e grupo Record com 5 redes cada um, 4 são de propriedade do grupo RBS e 3 do grupo Folha.

Assim, uma das conclusões obtidas pelo Informe foi a de que a democracia brasileira corre graves riscos devido à propriedade cruzada. A configuração da propriedade cruzada é percebida quando um grupo possui diferentes tipos de mídia.

\subsection{CENSURA E REGULAÇÃO DA MÍDIA}

Historicamente, é possível identificar a censura desde o período da colonização do país. No entanto, este artigo optou por analisar, como forma de exemplo, alguns aspectos da censura à mídia durante a ditadura militar (1964-1985). Uma das principais marcas deixadas pelo primeiro presidente da ditadura, Castello Branco, foi a sanção da Lei 5.250, de 9 de fevereiro de 1967, conhecida como Lei de Imprensa. Com a promulgação da lei, o Ministério das Comunicações poderia apreender jornais e revistas. Todavia, foi com o Ato Institucional n ${ }^{\circ}$ 5, de 13 de dezembro de 1968, que os veículos de comunicação efetivamente sofreram forte repressão. Segundo Sergio Mattos,

[...] muitos jornais, grandes e pequenos, foram invadidos, empastelados ou lacrados pela força policial. Muitos diretores de jornais foram presos. O Estado de São Paulo, Jornal da Tarde e Jornal do Brasil tiveram edições apreendidas, enquanto a Tribuna

9 G1. Disponível em: <https://g1.globo.com/economia/midia-e-marketing/noticia/tv-e-o-meiopreferido-por-63-dos-brasileiros-para-se-informar-e-internet-por-26-diz-pesquisa.ghtm>.

Acesso em 14 jun. 2018. 
da Imprensa foi submetida a oito anos de censura prévia e seu diretor, Hélio Fernandes, preso inúmeras vezes. Vários outros jornais e revistas estiveram também sob censura, em períodos contínuos ou não, em todo o território nacional $[\ldots]^{10}$.

Entre os assuntos censurados, prossegue o autor, "estouro de aparelhos subversivos, prisões, torturas e até mesmo alguns sobre epidemias que estavam ocorrendo em algum local do país, como um surto de hemorragia em crianças provocado por mosquitos da região de Altamira, em 1972" ${ }^{11}$.

Por sua vez, o mandato de Médici encarregou-se de pressionar as emissoras de televisão, o controle exercido sobre a televisão, principalmente nos telejornais, desde multas até a proibição de programas, influenciou diretamente a opinião pública, mascarou, manipulou e escondeu a realidade do país.

Durante os anos da ditadura militar, houve inúmeras violações aos direitos e liberdades fundamentais. Por isto, a Constituição Federal zelou por assegurar a liberdade de expressão, o direito à informação, a liberdade de manifestação do pensamento da população por meio dos jornais, revistas, rádio, televisão, internet, além de proteger a liberdade dos veículos de comunicação, proibindo qualquer tipo de censura ou restrição.

Em 2009, o STF (Supremo Tribunal Federal) julgou a ADPF 130, proposta pelo partido político PDT. Na ocasião, os ministros do STF decidiram que a imprensa deve ser livre, desde que observados os dispositivos da Constituição Federal de 1988.

No entanto, somente a liberdade nos meios de comunicação não é suficiente para fazer cumprir os princípios democráticos e republicanos elencados na ordem constitucional. Na visão do Ministro Joaquim Barbosa, a mídia deve ser diversa e plural, sendo dever do Estado garantir que isso ocorra, atuando em prol da liberdade de expressão e desobstruindo os grupos econômicos que exercem a hegemonia do mercado e cenário midiático $^{12}$.

Hoje, poucas famílias formam um conglomerado empresarial dentro do setor da mídia, parlamentares detentores de mandato eletivo são

\footnotetext{
${ }^{10}$ MATTOS, Sérgio. Mídia Controlada: A história da censura no Brasil e no mundo. São Paulo: Paulos, 2005.p 117.

${ }^{11}$ Id., Ibid. p. 119.

${ }^{12}$ BRASIL. Supremo Tribunal Federal. Arguição de Descumprimento de Preceito Fundamental 130, Brasília, 30 abril 2009. Disponível em: < http://redir.stf.jus.br/paginadorpub/paginador.jsp?docTP=AC\&docID=605411 > Acesso em 24 jul 2018
} 
sócios ou donos de empresas concessionárias de radiodifusão, programas religiosos foram propagados através da prática ilegal de aluguel da programação. Destarte, o quadro dos meios de comunicação está longe do ideal democrático e da Constituição Federal, que pressupõem veículos livres, plurais e diversos.

Esses atos ilegais decorrem devido a ausência de um marco regulatório da mídia no Brasil. As leis que tratam da radiodifusão são um emaranhado confuso e desatualizado, inaptas a fazer com que seus comandos sejam observados, sendo facilmente descumpridas. A falta de fiscalização pelas agências reguladoras permite que essas ilegalidades ocorram diariamente, tendo em vista que o Poder Judiciário é demasiadamente moroso. Ademais, diversos comandos constitucionais para a comunicação social não foram regulados em lei.

Defende-se a regulação econômica da mídia por dois motivos: a concentração do mercado por poucos agentes econômicos é facilitada pela falta de um marco regulatório. A hegemonia exercida impede que os canais de informação sejam acessíveis, plurais e diversos. Assim, vive-se em uma falsa representação de democracia, onde o povo não consegue participar efetivamente das decisões políticas e a informação é fortemente controlada $^{13}$. Além disso, a concentração fere o princípio da livre concorrência, sendo a comunidade a principal prejudicada, já que a concorrência não é correta e leal.

Atualmente, a regulação da mídia no Brasil gera posicionamentos controversos, sendo erroneamente associada pela mídia à censura ou ao controle dos meios de comunicação pelo Estado, ou, por vezes, o debate é omitido da população. O discurso da mídia tradicional é uma das principais causas desse desconhecimento do assunto, frequentemente reforçando antigos chavões como 'controle da mídia pelo governo' ou 'ofensa à liberdade de imprensa e à liberdade de expressão, 14 .

Durante as eleições de 2014, a candidata à Presidência da República pelo PT (Partido dos Trabalhadores), Dilma Roussef, tinha em seu plano de governo o debate em torno da regulação econômica da mídia, com foco no combate ao monopólio e oligopólio da comunicação social. Porém, a repercussão do tema encontrou forte resistência. No mesmo ano de 2014, o Estado de São Paulo, em sessão da opinião oficial do jornal

\footnotetext{
${ }^{13}$ CHOMSKY, Noam. Mídia: propaganda política e manipulação. Tradução de Fernando Santos. São Paulo: WMF martinsfontes, 2017.

${ }^{14}$ VANNUCHI, Camilo Morano. A regulação dos meios de comunicação no discurso dos jornais. Revista Alterjor: Grupos de Estudos Alterjor: jornalismo popular e alternativo, São Paulo, v. 01, p.22-38, janeiro/junho, 2018.
} 
afirmou que o projeto do PT consistia em "controlar os meios de comunicação para viabilizar seu projeto de manutenção do poder a qualquer custo" 15 .

Em entrevista à emissora de rádio $\mathrm{BBC}$ News Brasil, o expresidente da Abert (Associação Brasileira de Emissoras de Rádio e Televisão) Daniel Slaveiro, ao ser questionado sobre a regulação pretendida pela candidata Dilma Roussef, afirmou que a mídia no Brasil "já é regulada" e "qualquer coisa que interfira no conteúdo tem repulsa e rechaço não só por parte dos veículos e profissionais como da sociedade como um todo, que considera a liberdade de imprensa um dos pilares da democracia" ${ }^{16}$.

De outro modo, para Fabio Konder Comparato, o discurso criado pelas emissoras de rádio e televisão, ao invocarem a liberdade de expressão dos meios de comunicação para invalidar a regulação da mídia, é incorreto e confunde-se liberdade de expressão e liberdade de empresa. Para o autor:

A lógica da atividade empresarial, no sistema capitalista de produção, funda-se na lucratividade, não na defesa da pessoa humana. Uma organização econômica voltada para a produção do lucro e sua ulterior partilha entre capitalistas e empresários não pode, pois, apresentar-se como titular de direitos inerentes à dignidade da pessoa humana. Ora, a liberdade de expressão não se confunde com liberdade de exploração empresarial nem é, de modo algum, garantida por ela ${ }^{17}$.

Portanto, a regulação da mídia nada tem a ver com censura ou controle dos meios de comunicação, não fere a liberdade de expressão. $\mathrm{O}$ marco regulatório está inserido na ordem constitucional, sendo pressuposto para a consolidação do regime democrático e dos postulados do Estado Democrático de Direito.

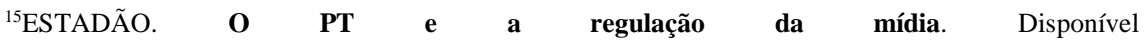
em: $\langle\underline{\text { https://opiniao.estadao.com.br/noticias/geral,o-pt-e-a-regulacao-da-midia-imp-,1514002. }>}$ Acesso em: 3 jul. 2018.

${ }^{16} \mathrm{BBC}$. O que significa regular a mídia?. Disponível em: 〈https://www.bbc.com/portuguese/noticias/2014/11/141128 regulacao_midia_lab > Acesso em: 3jul 2018.

${ }^{17}$ COMPARATO, Fábio Konder. A democratização dos meios de comunicação de massa. Revista USP. São Paulo, n 48, p. 6-17, dez/fev. 2000-2001.
} 


\section{OS PROBLEMAS CAUSADOS PELA FALTA DE REGULAÇÃO}

\subsection{O ALUGUEL DE HORÁRIOS DA PROGRAMAÇÃO ÀS IGREJAS}

A utilização dos meios de comunicação de massa pelas igrejas é feita através da disponibilização de horários da grade de programação de emissoras concessionárias de rádio e televisão, em troca de alugueis cobrados. O professor Eugênio Bucci aponta para o fato de que a principal causa para a ocorrência da influência religiosa nos meios de comunicação é a falha no próprio sistema da radiodifusão.

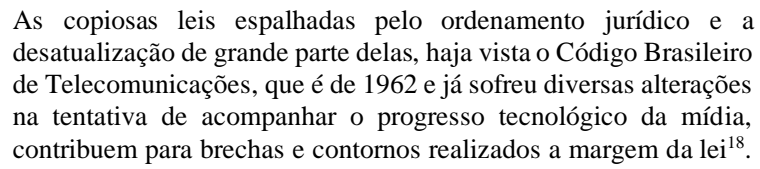

Outros dois fatores influenciadores são a falta de fiscalização por parte Agência Nacional de Telecomunicações (Anatel), agência reguladora responsável, e a morosidade do Poder Judiciário, quando se depara com ações ajuizadas pelo Ministério Público, no exercício da função de fiscal da lei.

O Informativo de Acompanhamento do Mercado da TV Aberta produzido pela Ancine (Agência Nacional de Cinema), monitorou a programação das principais emissoras de canal aberto no Brasil, entre as quais, Rede Globo, SBT, TV Brasil, TV Gazeta, CNT, Record TV, Rede TV, TV Cultura e Band. Dividiu-se a programação das emissoras em cinco categorias: entretenimento, informação, educação, publicidade e outros.

Os programas religiosos, objeto deste estudo, encontram-se no gênero religioso, incorporado à categoria 'Outros'. A edição de 2016 do Informe de TV Aberta ressaltou a dominância e crescimento deste gênero desde 2012.

O percentual dos programas religiosos na grade da TV aberta em 2012 era de $14 \%$, já ocupando a liderança na grade dentro da categoria. No ano de 2013, a presença de programas religiosos aumentou, chegando a um percentual de 16\%. Da mesma forma, nos anos subsequentes de 2014, 2015

${ }^{18}$ BUCCI, Eugênio. O Estado de Narciso. São Paulo: Companhia das Letras, [s.1.], 2015. p. 112. 
e 2016, a prevalência desse gênero se sustentou, ultrapassando, em 2016, a porcentagem de $21 \%$, passando a ocupar $1 / 5$ do total de toda a programação de televisão brasileira.

Através do Informe foi possível analisar separadamente o conteúdo da programação de cada canal constante da pesquisa. O canal CNT, desde 2012, disponibiliza $89,6 \%$ de sua grade de programação à Igreja Universal do Reino de Deus. A rede Record, rede pertencente ao Bispo Edir Macedo, disponibiliza 22\% de sua grade para divulgar conteúdo de cunho religioso da Igreja Universal, igreja em que Edir Macedo é líder ${ }^{19}$.

Em 2014, o Ministério Público Federal de São Paulo ajuizou as ações civis públicas, de $\mathrm{n}^{\circ}$ 0022869-77.2014.403.6100 e $\mathrm{n}^{\circ}$ 002287062.2014.403.6100 para invalidar as outorgas do serviço de radiodifusão concedidas à Rede 21 Comunicações S/A e ao grupo CNT. Segundo o MPF, as respectivas emissoras de televisão venderam 22 horas de toda a grade diária, inclusive nos finais de semana, à Igreja Universal do Reino de Deus, com a finalidade de veicular programa de interesse da entidade religiosa.

O Ministério Público sustenta a tese de que as redes excederam manifestamente o limite legal. O Decreto 52.795, de 1963, admite a disponibilização de $25 \%$ do horário da programação para a publicidade. Com a venda de publicidade, as emissoras são remuneradas pelo serviço prestado. Contudo, esse limite não pode ser ultrapassado, pois a radiodifusão, serviço de interesse público, deve atender as finalidades educativa, artística, cultural e informativa, conforme define a Constituição Federal. Assim, o lucro de emissoras não pode ser o seu principal fim.

Em esclarecimentos concedidos à TV Brasil, Comparato endossou a ilegalidade praticada pela Igreja Universal e os canais Rede 21 e CNI. O autor atenta-se para o fato de que a cessão de poderes de uso e gozo da radiodifusão a um terceiro configura a chamada subconcessão, permitida pelo ordenamento jurídico desde que observadas determinadas $\operatorname{regras}^{20}$.

O artigo 26, caput, da lei 8.987, de 13 de fevereiro de 1995, que trata sobre o regime de concessão e permissão dos serviços públicos dispõe que a subconcessão só poderá ser concedida mediante autorização expressa

\footnotetext{
19 ANCINE. Infome de acompanhamento do mercado de tv aberta. 2016. Disponível em 〈https://oca.ancine.gov.br/sites/default/files/repositorio/pdf/informe tvaberta 2016.pdf $>$ Acesso em: 14 jan 2018.

${ }^{20} \mathrm{TV}$ BRASIL. Ver TV debate aluguel do espectro de radiodifusão. Disponível em: 〈http://tvbrasil.ebc.com.br/vertv/episodio/ver-tv-debate-aluguel-do-espectro-de-radiodifusao〉. 
do Poder Público. Os canais de televisão e rádio que realizam este tipo de prática estão, na verdade, descumprindo o contrato previamente firmado com o Poder Público. Infelizmente, o Poder Judiciário é extremamente moroso. Enquanto a ação civil pública não é julgada, os canais Rede $21 \mathrm{e}$ CNT continuam transmitindo programas da Igreja Universal durante a programação diária, desrespeitando o contrato firmado com a Administração Pública e a própria Constituição.

\subsection{PARLAMENTARES DONOS DO SETOR DE RADIODIFUSÃO}

O Brasil passou por uma transição relativamente recente de regimes, onde, a cerca de trinta anos, saiu de um período ditatorial marcado por graves violações a direito e garantias fundamentais, e passou a ser um regime democrático, que se preocupou em não somente respeitar direitos e liberdades individuais, como também garantir o espaço de todos os cidadãos nas decisões políticas do país.

É certo que a falta de regulação dos meios de comunicação ocasiona diversos problemas que prejudicam substancialmente o regime democrático e a ordem constitucional. Entre as diversas falhas a serem analisadas no setor da radiodifusão, torna-se de suma importância tratar da participação de parlamentares, como sócios ou donos, de emissoras de rádio e televisão.

O vínculo entre parlamentares e os meios de comunicação é indissociável. Assim como o televangelismo, os políticos donos ou sócios de empresas concessionárias da radiodifusão penetraram no regime democrático sem maiores dificuldades, apesar de o Código Brasileiro de Telecomunicações, de 1962, já proibir expressamente a participação no serviço da radiodifusão quem estiver no "gozo da imunidade parlamentar ou de foro especial". No final do período ditatorial, inclusive, o Poder Executivo outorgou diversas concessões para o serviço da radiodifusão, em um curto lapso temporal, sendo a maior parte dos beneficiados políticos detentores de mandato eletivo ${ }^{21}$.

Após mais de duas décadas de ditadura, foi no governo do primeiro presidente civil, José Sarney (1985-1990), que a outorga de concessões públicas atingiu seu apogeu. Segundo Paulino Motter, “1.028

\footnotetext{
${ }^{21}$ SANKIEVICZ, Alexandre. Liberdade de expressão e pluralismo: Perspectivas de regulação. São Paulo: Saraiva, 2011. p. 132.
} 
outorgas foram assinadas durante o Governo Sarney entre 1985 e 1988 " 22. Das 1.028 outorgas assinadas, 91 foram para deputados e senadores que fizeram parte da elaboração da Constituição Federal de 1988. Durante anos, a distribuição de outorgas desse serviço público serviu como moeda de troca para aprovação de projetos de interesses políticos.

\subsubsection{VEDAÇÃO CONSTITUCIONAL E OS RISCOS DA PARTICIPAÇÃO POLÍTICA NA RADIODIFUSÃO}

Desde a expedição do diploma, preceitua o art. 54 da Constituição, os parlamentares não poderão firmar ou manter contrato, aceitar ou exercer cargo, função ou emprego remunerado com pessoa jurídica de direito público, autarquia, empresa pública, sociedade de economia mista ou empresa concessionária de serviço público, exceto quando o contrato obedecer a cláusulas uniformes. E desde a posse, não poderão ser proprietários, manter controle ou direção de empresa que goze de favor decorrente de contrato com pessoa jurídica de direito público, ou nela exerça função remunerada. Conquanto a vedação constitucional seja clara, discute-se atualmente sobre a pertinência desse artigo constitucional.

O Presidente Michel Temer, por intermédio da AGU (Advocacia Geral da União) ajuizou uma ADPF para declarar inconstitucionais decisões do Poder Judiciário. De acordo com a ADPF 429, o Ministério Público vem ajuizando ações civis públicas, com a finalidade de cancelar ou não renovar concessões públicas outorgadas às empresas com parlamentares em seu quadro societário, ou impedir políticos detentores de mandato eletivo de participar do serviço da radiodifusão.

A AGU afirma que essas decisões interpretam erroneamente o artigo 54, I, alínea 'a' da Constituição Federal, além de ofenderem preceitos fundamentais. Essas proibições feririam os valores sociais do trabalho e da livre iniciativa, a ordem econômica, a liberdade de manifestação do pensamento, criação, expressão e a informação, bem como direitos fundamentais previstos no artigo $5^{\circ}$ da Constituição Federal $^{23}$.

\footnotetext{
${ }^{22}$ MOTTER, Paulino. O uso político das concessões das emissoras de rádio e televisão no governo Sarney. Comunicação e Política, v.1,n.1,p 89-115, ago/nov. 1994.

${ }^{23}$ BRASIL. Supremo Tribunal Federal. Arguição de Descumprimento de Preceito Fundamental 429. Brasília, 9nov 2016. Disponível em: <https://artigo19.org/centro/wpcontent/uploads/2017/04/ADPF-429.pdf> Acesso 1 ago 2018.
} 
A despeito do entendimento de que o artigo 54 não tem o condão de vedar deputados e senadores de serem donos ou sócios de empresas de radiodifusão, a Ministra Rosa Weber, em 2016, indeferiu o pedido liminar para invalidar as decisões do Poder Judiciário que proibiram políticos participar do quadro societário das emprestas que prestadoras do serviço de radiodifusão, pois, segundo a Ministra, não foi possível constatar equívoco na interpretação do artigo ora questionado ${ }^{24}$.

Não obstante, o próprio Supremo Tribunal Federal na Ação Penal $530^{25}$, que julgou a falsificação de um deputado federal para esconder a participação em uma empresa de radiodifusão, confirmou a vedação constante do artigo 54.

O coronelismo eletrônico é uma prática antiga bastante recorrente no Brasil. Todavia, não só a ilegalidade é observada. Atualmente, existe um grande conflito de interesses, tendo em vista que a Constituição brasileira incluiu a participação do Congresso Nacional para a outorga e renovação de concessão, permissão ou autorização e emissoras de rádio e televisão. Isto é, os parlamentares possuem um papel fundamental na análise, e quando outorgam concessões aos próprios membros do Congresso, ferem o interesse público.

Em 2015, o partido político PSOL (partido socialismo e liberdade) ajuizou a ADPF 379 perante o Supremo Tribunal Federal, para questionar a participação de 32 deputados federais e 8 senadores detentores de mandato eletivo em empresas da radiodifusão. Segundo o PSOL, um dos preceitos violados é o art. 54, já que a participação de políticos na radiodifusão é incompatível com o exercício do mandato. No mesmo seguimento, o partido pede pela cassação dos mandatos dos deputados e senadores, conforme o art. 55, I, da Constituição ${ }^{26}$.

Levando-se em consideração o fato de que a televisão é o meio mais utilizado entre os brasileiros para buscar informação, a utilização dos meios de comunicação por deputados e senadores pode deturpar a

\footnotetext{
${ }^{24}$ MIGALHAS. STF mantém decisões que impedem concessão de rádio e TV a empresas que têm políticos como sócios. Disponível em: <https://www.migalhas.com.br/Quentes/17,MI249932,91041-

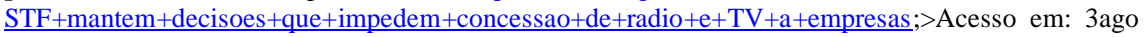
2018

${ }^{25}$ SUPREMO TRIBUNAL FEDERAL.Condenado por falsidade ideológica, deputado tem pena prescrita. Disponível

em: $\langle$ http://www.stf.jus.br/portal/cms/verNoticiaDetalhe.asp?idConteudo=274755 $>$. Acesso em 10 ago 2018.

${ }^{26}$ BRASIL. Supremo Tribunal Federal. Ação de Descumprimento de Preceito Fundamental 379. Brasília, 5 dez 2015. Disponível em: <http://artigo19.org/centro/wp-content/uploads/2017/04/ADPF379.pdf>. Acesso em: 27 jul 2018.
} 
construção e manipular a opinião pública. A influência de políticos na mídia pode causar imensos danos à democracia.

O controle exercido pelos políticos impede a divulgação de informações e notícias diversas e livres, já que por trás da apropriação dos meios existem interesses políticos, voltados para o proveito do próprio parlamentar. Consequentemente, a restrição de informações divulgadas impede a fiscalização dos atos dos representantes eleitos pelo Poder Público e o próprio povo.

\section{CONCLUSÃO}

O principal escopo de todo o trabalho foi o de identificar e estudar algumas das falhas existentes no setor midiático. O tema escolhido possui notável relevância social, uma vez que a maior parte dos relacionamentos sociais se dá por intermédio das diversas mídias existentes. As pesquisas demonstraram a elevada função social exercida pelos meios de comunicação. A mídia é capaz de repercutir desde a esfera privada dos indivíduos até a esfera pública, atuando diretamente na formação da opinião pública.

Assim como qualquer outro serviço público, a radiodifusão precisa obedecer a algumas regras específicas. Hoje, no Brasil, isso não se verifica. A legislação que disciplina os meios de comunicação é extremamente desatualizada, tanto pelo aspecto temporal quanto pela evolução da infraestrutura da mídia. Verificou-se que a principal causa de o cenário ser assim é devido à falta de um marco regulatório definitivo, que reúna e atualize as leis espalhadas pelo ordenamento jurídico. $\mathrm{Na}$ conjuntura da sociedade brasileira, é possível identificar no espaço público a presença de oligopólios, propriedade cruzada, vínculos políticos e penetração de religiões.

\section{REFERÊNCIAS BIBLIOGRÁFICAS}

ANCINE. Infome de acompanhamento do mercado de tv aberta. 2016. Disponível em $<$ https://oca.ancine.gov.br/sites/default/files/repositorio/pdf/informe_tvaberta_2016.pdf> Acesso em: 14 jan 2018. 
BBC. O que significa regular a mídia?. Disponível em:

<https://www.bbc.com/portuguese/noticias/2014/11/141128_regulacao_midia_lab> Acesso em: 3jul 2018.

BOBBIO, Norberto. A Era dos Direitos. Tradução de Carlos Nelson Coutinho. Rio de Janeiro: Elsever, 2004.

BRASIL. Supremo Tribunal Federal. Arguição de Descumprimento de Preceito Fundamental 130, Brasília, 30 abril 2009. Disponível em: < http://redir.stf.jus.br/paginadorpub/paginador.jsp?docTP=AC\&docID=605411 > Acesso em 24 jul 2018

BRASIL. Supremo Tribunal Federal. Ação de Descumprimento de Preceito Fundamental 379. Brasília, 5 dez 2015. Disponível em: <http://artigo19.org/centro/wp-content/uploads/2017/04/ADPF379.pdf>. Acesso em: 27 jul 2018.

BUCCI, Eugênio. O Estado de Narciso. São Paulo: Companhia das Letras, [s.1.], 2015.

COMPARATO, Fábio Konder. A democratização dos meios de comunicação de massa. Revista USP. São Paulo, n 48, p. 6-17, dez/fev. 2000-2001.

CHOMSKY, Noam. Mídia: propaganda política e manipulação. Tradução de Fernando Santos. São Paulo: WMF martinsfontes, 2017.

ESTADÃO. O PT e a regulação da mídia. Disponível em:<https://opiniao.estadao.com.br/noticias/geral,o-pt-e-a-regulacao-da-midia-imp-,1514002.> Acesso em: 3 jul. 2018.

G1. Disponível em: <https://g1.globo.com/economia/midia-e-marketing/noticia/tv-e-o-meiopreferido-por-63-dos-brasileiros-para-se-informar-e-internet-por-26-diz-pesquisa.ghtm>. Acesso em 14 jun. 2018

MATTOS, Sérgio. Mídia Controlada: A história da censura no Brasil e no mundo. São Paulo: Paulos, 2005.

MIGALHAS. STF mantém decisões que impedem concessão de rádio e TV a empresas que têm políticos como sócios. Disponível em: <https://www.migalhas.com.br/Quentes/17,MI249932,91041$\mathrm{STF}+$ mantem+decisoes+que+impedem+concessao+de+radio+e+TV+a+empresas; >Acesso em: 3ago 2018

MOTTER, Paulino. O uso político das concessões das emissoras de rádio e televisão no governo Sarney. Comunicação e Política, v.1,n.1,p 89-115, ago/nov. 1994.

BRASIL. Supremo Tribunal Federal. Arguição de Descumprimento de Preceito Fundamental 429. Brasília, 9nov 2016. Disponível em: <https://artigo19.org/centro/wp-content/uploads/2017/04/ADPF429.pdf> Acesso 1 ago 2018.

NAPOLITANO, Carlo José. A regulação constitucional da comunicação social e a efetivação de suas normas. ALCEU: Revista de Comunicação, cultura e política, Rio de Janeiro, v. 12, n. 24, p.204-215, jan./jun. 2012. 
SANKIEVICZ, Alexandre. Liberdade de expressão e pluralismo: Perspectivas de regulação. São Paulo: Saraiva, 2011.

SILVA, José Afonso. Curso de Direito Constitucional Positivo. 37 edição. São Paulo: Malheiros, 2014.

STRECK, Lenio Luiz; MORAIS, José Luis Bolzan de. Ciência Política e Teoria Geral do Estado. 2. ed. Porto Alegre: Livraria do Advogado, 2001. p. 94

SUPREMO TRIBUNAL FEDERAL.Condenado por falsidade ideológica, deputado tem pena prescrita. Disponível em:

<http://www.stf.jus.br/portal/cms/verNoticiaDetalhe.asp?idConteudo=274755>. Acesso em 10 ago 2018.

TV BRASIL. Ver TV debate aluguel do espectro de radiodifusão. Disponível em:

〈http://tvbrasil.ebc.com.br/vertv/episodio/ver-tv-debate-aluguel-do-espectro-de-radiodifusao〉.

Acesso em 19 dez 2017

VANNUCHI, Camilo Morano. A regulação dos meios de comunicação no discurso dos jornais. Revista Alterjor: Grupos de Estudos Alterjor: jornalismo popular e alternativo, São Paulo, v. 01, p.22-38, janeiro/junho, 2018.

VOGEL, Luiz Henrique. A comunicação social na constituição de 1988 e a concentração de mídia no Brasil (Consultoria Legislativa). Brasília: Câmara dos Deputados, 2013. 